http://jmscr.igmpublication.org/home/ ISSN (e)-2347-176x ISSN (p) 2455-0450

crossref DOI: https://dx.doi.org/10.18535/jmscr/v7i11.05

\author{
Journal Of Medical Science And Clinical Research \\ IGM Publication \\ An Official Publication of IGM Publication
}

\title{
Rare Presentation of Neurilemmoma Mimicking Malignancy: A Case Report
}

Authors

Parikshita Dalai $^{1}$, Archana Kumari Acharya ${ }^{2}$

${ }^{1}$ Associate Professor, ${ }^{2}$ Junior Resident

Abstract

Neurilemmoma is a benign nerve sheath tumor where surgical excision is the treatment of choice. Here we present a rare case of neurilemoma that mimics malignant soft tissue tumor.

This patient presented with atypical history of a irregular huge mass on left thigh with clinical as well as investigative findings suggestive of a malignant soft tissue tumor. The mass was excised and excisional biopsy came out to be a neurilemmoma.

Keywords: Neurilemmoma, Atypical Presentation, Mimicking Malignancy.

\section{Introduction}

Neurilemmoma is a benign encapsulated peripheral nerve sheath tumor., arising from Schwann cells. Presents usually slow growing mass;

Occasionally associated with pain and muscular weakness. Usually measures $3-8 \mathrm{~cm}$ and complete surgical excision is the treatment of choice. A malignant soft tissue tumor. It is a non encapsulated tumor of mesodermal origin.

Usually presents as a mass with rapid increase in size. May be associated with weight loss.

The extremities are the most common site of presentation. Surgical excision with margin and chemotherapy etc is treatment of choice. ${ }^{[8]}$

Here is an uncommon case of a benign nerve sheath tumor mimicking malignancy.

\section{Case Report}

A 26 yr old male presented with a mass on left thigh for the last $5 \mathrm{yrs}$ which was shown to have rapid increase in size over the last 8 months to reach a present size of $30 * 20 \mathrm{~cm}$. Patient gives a history of trauma 1month back following which he developed an ulcer over the mass. He also has a history of wt loss of $8 \mathrm{~kg}$ over the last 10 month. Patient doesn't have muscle weakness and could carry out normal daily activities.

\section{On examination}

a. On inspection

A large multilobulated, irregular mass of $30 \mathrm{~cm} \times 20$ $\mathrm{cm}$ on the lateral aspect of left thigh extending from mid thigh to just above the knee and horizontally extending from anterior aspect to whole of lateral surface of thigh Visible veins were present surrounding the mass and over it .

An ulcer of size $4 \mathrm{~cm} \times 3 \mathrm{~cm}$ over the proximal end of the mass with irregular margin and, minimal serous discharge.

\section{b. On palpation}

There is local rise of temp and No tenderness; shape is irregular mulitlobular. Variegated in consistency. surface is irregular. Mobility is restricted in longitudinal direction as compared to horizontal direction. It has well defined irregular margin. Skin 
over the mass was free and an this present. attachment to the underlying structure couldn't be elicited.

No palpable lymph nodes.no bruit could be auscultated.

\section{On Investigation}

Routine base line blood investigation were in the normal range.

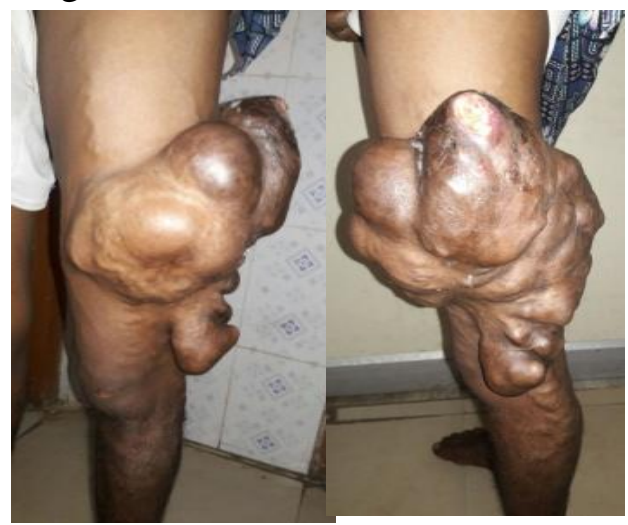

Fig. 1 Frontal and lateral view

X-Ray: left thigh showed a huge soft tissue mass on the lateral aspect. free from bone, Cortex intact. Suggest the mass is not arising from the bone.

$\mathrm{X}$ ray chest $\mathrm{PA}$ view had no evidence of metastatic lesion.

PUNCH BIOPSY of the lesion showed stratified squamous epithelium only with extensive areas of necrosis and polymorphs only.

MRI. Showed left mid lateral aspect parietal plane avidly enhancing lobulated expansile mass as noted with $\mathrm{T} 1 \mathrm{~W}$ isointense $\mathrm{T} 2 \mathrm{~W}$ intermediate to hyperintense signal encroaching vastus lateralis muscle favors a diagnosis of soft tissue sarcoma.

MRA shows the mass has exaggerated feeders from SFA and profunda femoris artery.

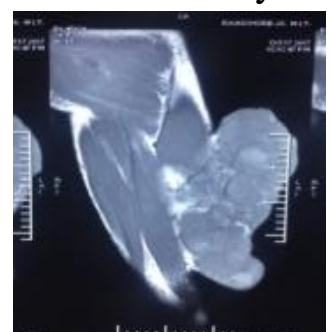

Fig.2a- Mass encroaching on the vastus lateralis muscle

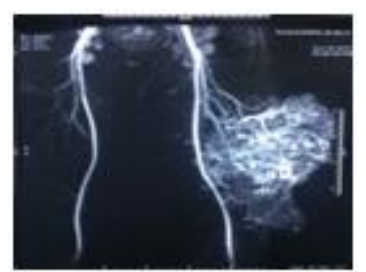

Fig. 2b-Avidly enhanced lesion on MRI

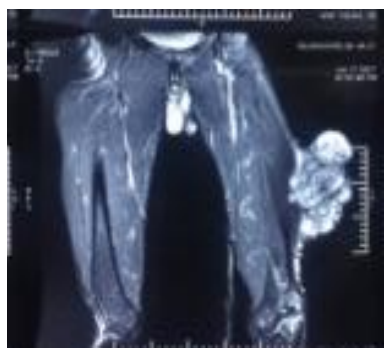

Fig 2c Exaggerated feeders from SFA and profunda femoris A.

\section{Discussion}

A young male presenting with a huge mass on left thigh for the last 5 yrs. with rapid increase in size over the last 8 months and associated wt loss likely suggested to a malignant growth was then planned for surgical excision with wide margin.

Clinically the tumor was suspected to be a malignant soft tissue sarcoma probably $\mathrm{MFH}$ (malignant fibrous histiocytoma) $28 \%$ of all STS or liposarcoma (15\% of all STS). These two are most common of soft tissue sarcomas. ${ }^{[1]}$ secondly most STS present as exophytic lesion in young to aged males. ${ }^{[2]}$

$50-60 \%$ of them present on extremities, with this huge size they tend to metastasize to lungs via hematogenous route.

Whereas neurilemmoma usually presents as a slow growing uninodular mass ${ }^{[9]}$.

Usual age of presentation is $20-50 \mathrm{yr}$ mc site is head /neck >flexors UL $>$ LL.

$90 \%$ are sporadic solitary mass.

- The MRI shows muscular encraochment. $\mathrm{T} 2 \mathrm{~W}$ intermediate to hyperintense.

- Whereas schwannoma shows well circumscribed capsular mass T2W hyperintensity signal. and split fat sign positive

- the management protocol is as follows: 
establish diagnosis ( ct or usg guided FNA /CORE NEEDLE BIOPSY)

$\checkmark$ Asses the disease spread (XRAY/MRI/CT)

$\checkmark$ Wide excision with $1-2 \mathrm{~cm}$ margin. [+/chemo therapy. $]^{[1]}$

- For a neruilemmoma complete excison is the $\mathrm{t} / \mathrm{t}$ of choice. Recurrence after excision is rare.

- Complete en block excsion was done and the gross specimen was showing well circumscribed multiple nodules with few cystic areas with areas of necrosis and hemorrhage

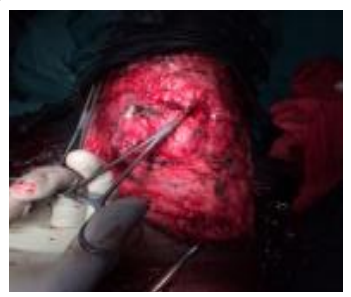

Fig 3a. Intraoperative image of the mass

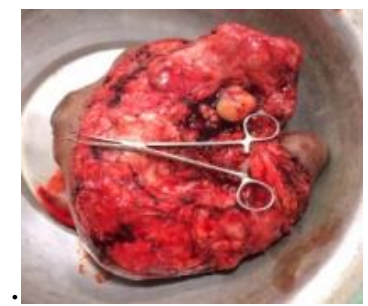

Fig 3b: Gross section after enbloc excision

- Microsections showed Antoni A and Antoni $\mathrm{B}$ area verocay bodies in Antoni A and dilated thrombosed vessels in Antoni B area and ares of granular calcification. ${ }^{[2]}$

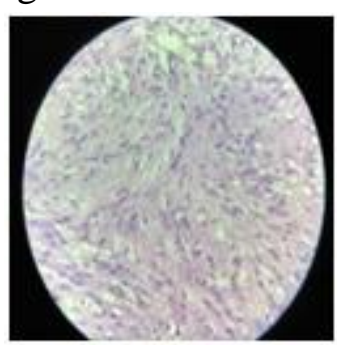

Fig 4a. Verocay bodies A and B

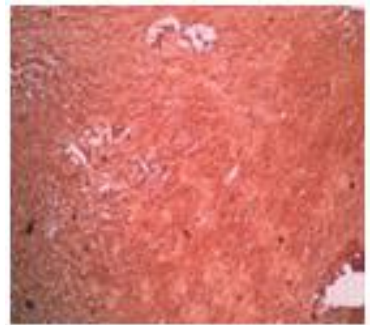

Fig 4b S100 positive IHC in our lab and a immunohistochemistry stain of protien S100 was shown to be positive. ${ }^{[2]}$

- Which confirmed the mass to be a benign peripheral nerve sheath tumor NEURILEMMOMA.

- Malignt change in neurilemomma is rare. ${ }^{[1][9]}$

- For immunohistochemical confirmation $\mathrm{S} 100$ is useful.s100 is an acidic protien marker for supporting cells in CNS/PNS. ${ }^{[7]}$

- When small they may resemble neurofibroma. When larger they present as a eccentric mass nerve of origin may be obliterated.

- This type of presentation is usually seen in Plexiform neurilemmoma which has $<5 \%$ incidence $^{[9]}$

\section{Conclusions}

Usually schwannoma presents as a slow growing asymptomatic mass but in this case it presented as a large multinodular mass with clinical and radiological features mimicking malignant soft tissue tumor which is a rare presentation.

\section{Acknowledgement}

All the information and pictures are taken with consent of the patient and all are considered to be true without any conflict of interest the case report was done with joint venture of department of general surgery and pathology of SCB medical college.

\section{References}

1. Schwartz's principles of surgery $9^{\text {th }}$ ed

2. Diagnstic histopathlogy of tumor $4^{\text {th }}$ ed

3. Haaga lanzieri gilkeson $\mathrm{CT}$ and $\mathrm{MR}$ imaging of the whole body $4^{\text {th }}$ ed

4. A case of infected schwannoma mimicking malignant tumor World J Surg Oncol. 2016; 14: 302 Published online 2016 Dec. doi: 10.1186/s12957-016-1058-3 PMCID: PMC5141643

5. Ancient schwannoma of the thigh mimicking a malignant tumour: a report of two cases, with emphasis on MRI findings 
Br J Radiol. 2010 Jul; 83(991): e154-e157

doi: $10.1259 / \underline{b j} / 19325350$

PMCID: PMC3473686

6. Robins and contran pathologic basis of diseases. $9^{\text {th }}$ ed

7. Diagnostic immunohistochemistry theranostic and genomic applications 3ed.

8. Concise textbook of surgery S DAS $5^{\text {th }}$ ed

9. Enzinger and weiss's soft tissue tumor $5^{\text {th }}$ ed.

10. Sternberg's Diagnostic surgical pathology $6^{\text {th }}$ ed. 